\title{
EL MOVIMIENTO INDIGNADO: COMUNICACIÓN POLÍTICA Y RELACIONES CON EL SISTEMA DE PARTIDOS
}

\author{
Ana María Juan Amat ${ }^{1}$. \\ Universidad Rey Juan Carlos de Madrid \\ Francisco Collado Campaña ${ }^{2}$ \\ Universidad Pablo de Olavide, Sevilla
}

http://dx.doi.org/10.5209/rev_NOMA.2013.v38.42904

Resumen.- El presente trabajo analiza la evolución de los indignados gracias a las redes sociales. De esta forma, se procede a un análisis del mensaje del 15-M como emisor y su posición respecto a la estructura partidista durante las elecciones generales.

Palabras clave.- indignados, comunicación política, elecciones generales, partidos políticos

\begin{abstract}
The present work analyses the evolution of the indignant thanks to the social networks. Of this form, it proceeds to an analysis of the message of the 15-M as emisor and its relations with political parties during general elections 2011.
\end{abstract}

Keywords.- indignant, political communication, general elections, political parties.

\section{EL MOVIMIENTO 15-M. SURGIMIENTO Y DESARROLLO}

"Nosotros los desempleados, los mal remunerados, los subcontratados, los precarios, los jóvenes... queremos un cambio y un futuro digno. Estamos hartos de reformas antisociales, de que nos dejen en el paro, de que los bancos que han provocado la crisis nos suban las hipotecas o se queden con nuestras viviendas, de que nos impongan leyes que limitan nuestra libertad en beneficio de los poderosos. Acusamos a los poderes políticos y económicos de nuestra precaria situación y exigimos un cambio de rumbo.", Democracia Real Ya, 2011.

Este comunicado de prensa se emitió el 17 de Mayo de 2011 junto a este otro: "Las prioridades de toda sociedad avanzada han de ser la igualdad, el progreso, la solidaridad, el libre acceso a la cultura, la sostenibilidad ecológica y el desarrollo, el bienestar y la felicidad de las personas." Como afirman las hermanas JuanAmat (Juan-Amat y Juan-Amat, 2012) "el embrión del 15-M se fue gestando a raíz de una concatenación de sucesos; la suma de una serie de factores cuya sincronía fue propiciando la creación, ya no del movimiento, sino de su puesta en marcha".

\footnotetext{
${ }^{1}$ Ana María Juan-Amat es doctoranda en Sociología por la URJC y Licenciada en Publicidad y Relaciones Públicas por la UA. Ha publicado diversos artículos y ponencias sobre publicidad y comunicación política en publicaciones especializadas.

${ }^{2}$ Francisco Collado es Máster en Ciencias Políticas por la UNED, Licenciado en Ciencias Políticas y de la Administración por la UPO y en Periodismo por la UMA. Ha publicado diferentes trabajos sobre comunicación política, élites políticas y teoría política.
} 
Por un lado, es necesario remontarse al concepto de indignación, más concretamente al momento en que éste aparece en las conciencia colectiva. El resultado de este surgimiento $y$, en cierto modo, de "toma de conciencia", es derivado de la precariedad social hacia la que ha ido decayendo el estado del bienestar español a lo largo de estos últimos años. Decadencia que ha ido acompañada de la mano de un sistema político con el que la sociedad española no se siente representada.

Por otro, a esto se le suma el lanzamiento del libro "Indignaos", escrito por Stéphane Hessel (2011), uno de los redactores de la Declaración Universal de Derechos Humanos de 1948. Hessel aboga por una insurrección pacífica, en detrimento de una indiferencia pasiva, invitando a los jóvenes a tomar conciencia y "cartas en el asunto". Previamente publicado en Francia y con altas repercusiones sociales sobre la percepción del status quo vigente por parte de los individuos, expande la conciencia a España donde sirve de golpe de efecto en las mentes de los conciudadanos.

Internet ha jugado un papel crucial en la intercomunicación, movilización y puesta en escena de todo el proceso del 15-M tomando a las redes sociales como principales herramientas de comunicación y acción social. Ismael Peña, Doctor en Sociedad de la Información y el Conocimiento y profesor en la Universidad Oberta de Cataluña -UOC-, lo expresa claramente: "el 15-M nació y se desarrolló en las redes sociales", es más afirma: "sin redes sociales, el movimiento 15-M no hubiese aparecido en absoluto".

\section{ESTRATEGIA LINGÜÍSTICA Y SIMBÓLICA DEL 15-M. LA TÉCNICA DE ANÁLISIS}

El método que se ha utilizado en este apartado de la investigación del 15-M abarca dos niveles básicos para obtener un amplio abanico de estudio, tanto mensurable a nivel cuantitativo, como de análisis del propio proceso a nivel cualitativo. Esta doble vertiente de análisis aportará mayor rigor científico y resultados más completos al cruzar ambos métodos.

\subsection{Nivel cuantitativo.}

En este punto, se realizará un análisis de contenido sobre las estrategias de comunicación del movimiento 15-M. En este análisis se engloba un "metanálisis" necesario como elemento que estudia, ya no sólo el contenido, sino la propia forma del contenido en sí; véase, como aclaración, una comparativa similar entre el qué se dice y el cómo se dice.

La muestra se basa en analizar toda la información relacionada con este tema en medios de comunicación con soporte digital: medios digitales (prensa, radio y televisión), plataformas clave del movimiento "indignaos" y documentales reeditados en digital.

Como variables principales a utilizar en el análisis de contenido, a continuación se 
exponen las mismas agrupadas -las dos primeras se engloban en el metanálisis del "cómo se dice" y la tercera en el "qué se dice"- y, a su vez, desagregadas en subvariables:

- $\quad$ En primer lugar, las funciones del lenguaje ejercen un papel clave en la construcción ideológica de los mensajes emitidos; por ende, se analizan sus orígenes en sus múltiples apariciones mediáticas con el fin de desvelar qué tipo de estrategia de comunicación lingüística ha sido utilizada y a qué función ha apelado en su mayor proporción.

- En segundo lugar, la imagen fotográfica juega un papel clave en la transmisión de contenidos como objeto complementario, en ocasiones, al texto. En este contexto del 15-M, se erige como elemento comunicativo evocador de información y emociones mientras acompaña al mensaje o es en sí misma un mensaje autónomo.

- $\quad$ En tercer lugar, y por último, el análisis de contenido contempla los issues tratados en las publicaciones emitidas por toda aquella información digital, bien sean plataformas o medios digitales, cuya fuente primaria de información son los indignaos del 15-M, máxime como sujeto emisor.

\subsubsection{Obtención de datos y análisis de la investigación cuantitativa}

La muestra analizada contempla 82 piezas documentales que abarcan diferentes medios en soporte digital: prensa, radio, televisión y páginas web oficiales. En ese compendio se han estudiado 46 soportes diferentes de medios de comunicación de masas. A continuación se exponen los resultados obtenidos (ver Gráfico I):

\section{GRÁFICO I. FUNCIONES LINGÜÍSTICAS DE LOS MENSAJES ANALIZADOS DEL 15-M}

\begin{tabular}{|l|c|c|}
\hline \multicolumn{1}{|c|}{$\begin{array}{c}\text { FUNCION DEL } \\
\text { LENGUAJE }\end{array}$} & TOTAL & PORCENTAJE \\
\hline Referencial & 93 & 20,43 \\
\hline Expresiva / Emotiva & 160 & 35,03 \\
\hline Apelativa & 130 & 28,46 \\
\hline Fática & 16 & 3,64 \\
\hline Poética & 33 & 7,29 \\
\hline Metalingüística & 23 & 5,10 \\
\hline TOTALES & 455 & 100 \\
\hline Fuente: Elaboración propia. \\
\hline
\end{tabular}


Como función predominante, se erige la emotiva. Los sentimientos, las emociones y las ideas del grupo adquieren presencia central en el discurso mediático. Es una función que se centra en el emisor, en este caso los emisores o el emisor como grupo, en la emoción que quieren transmitir en la comunicación.

A este dato le sigue en orden numérico el de la función apelativa del lenguaje, lo que indica la intención por parte de los "Indignaos" de argumentar, convencer y persuadir a su audiencia sobre aquello que demandan y denuncian. Esa demanda y denuncia, así como las peticiones y propuestas, vienen dadas por la función referencial del lenguaje, la cual se encuentra en la tercera posición en la escala del grueso del discurso.

En las últimas posiciones se encuentran las funciones poética, metalingüística y fática, respectivamente. La primera de ellas se utiliza en un $7 \%$ de la muestra analizada con el objetivo de embellecer y hacer atractivo el mensaje a sus oyentes. Configura una relación complementaria entre la combinación de elementos argumentativos, emocionales y poéticos en su uso mediático, máxime en titulares de prensa y medios audiovisuales. A esta función le siguen la metalingüística y la fática con un $23 \%$ y un $16 \%$, respectivamente.

Por lo tanto, en este apartado de análisis, en el cómo se dice lo que se dice, es de notable importancia aludir a la forma en la que los "Indignaos" se muestran y dirigen a la sociedad. En mayor grado, como grupo que demanda un cambio y lo hace a través de la emoción, utilizando la empatía para con los sentimientos que afectan al grueso de la población. Paralelamente, transmitiéndolos como grupo que aúna a los demás ciudadanos que piensan y sienten como ellos y, posteriormente, con una función del lenguaje apelativa o conativa que pretende persuadir a la audiencia a través de unos referentes o referenciales que se solicitan y se exponen mediáticamente como claves de la razón de ser del movimiento y como motores de cambio socio-político.

\section{GRÁFICO II. FUNCIONES DE LA IMAGEN QUE ACOMPAÑA A LOS MENSAJES DEL 15-M.}

\begin{tabular}{|l|c|c|}
\hline $\begin{array}{c}\text { FUNCION DE LA } \\
\text { IMAGEN }\end{array}$ & TOTAL F.I. & $\%$ \\
\hline Simbólica & 12 & 35,29 \\
\hline Epistémico & 21 & 61,76 \\
\hline Estética & 1 & 2,94 \\
\hline TOTALES & 34 & 100 \\
\hline Fuente: Elaboración propia \\
\hline
\end{tabular}


Recordando a Arnheim, en el modo epistémico, la imagen aporta informaciones visuales sobre el mundo, es decir, no arbitrarias, sino referentes a la realidad (Arnheim, 1976). Esta epistemología fotográfica tiene el primer puesto en el estudio de la imagen que acompaña al texto con un $61,76 \%$, lo cual no hace sino recordarnos y redundar en el hecho, así como mostrarnos un trozo o fragmento de ese hecho en un instante dado (ver Gráfico II).

A nivel simbólico, la investigación sobre la imagen desvela un segundo puesto con un $35,29 \%$ de las mismas. Seguidamente, con un 2,94\% le sigue la función de la imagen con fines estéticos. En éste caso, la imagen tiene la finalidad de complacer al receptor con su belleza apelando a sus sentidos; el aquél, las imágenes funcionan como símbolos laicos y como transmisores de valores ligados a las nuevas formas políticas como: democracia, libertad y progreso. Véase como ejemplo la siguiente imagen:

IMAGEN I. CARTEL DEL 15M

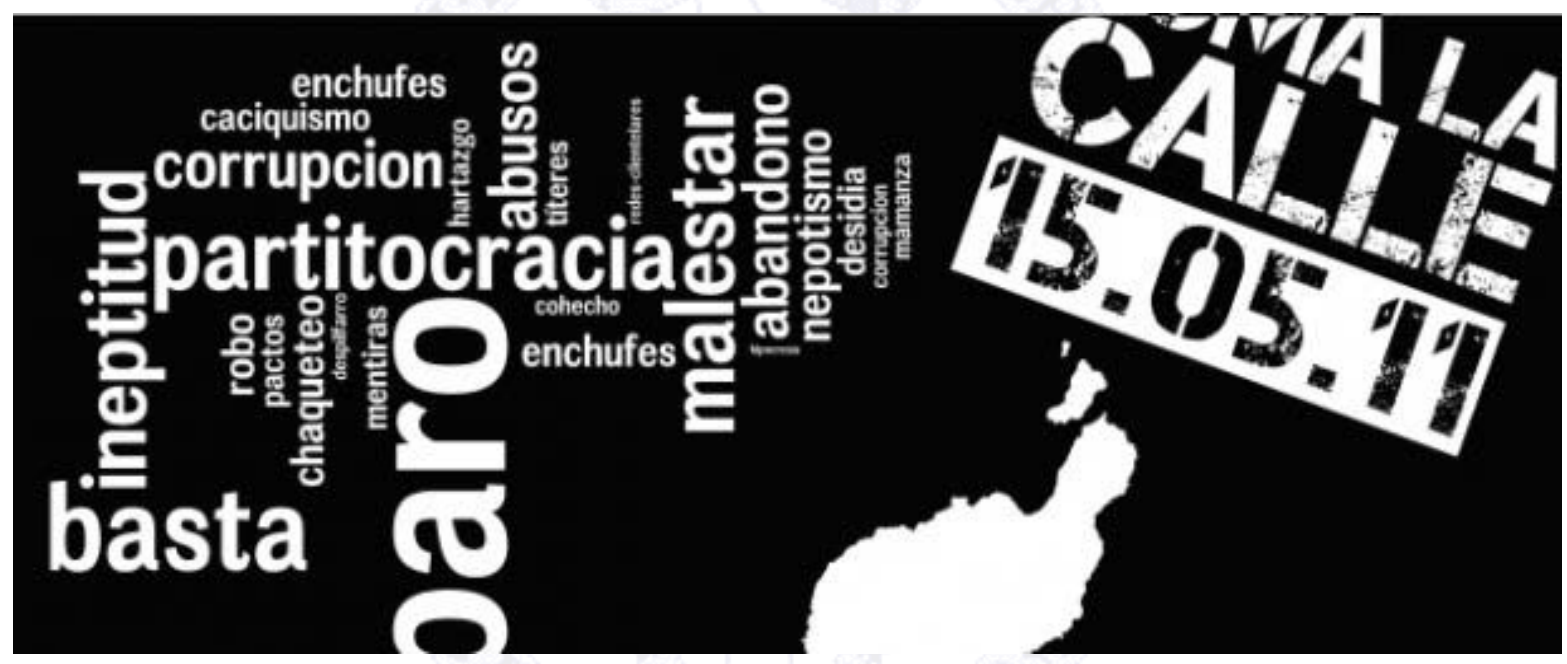

Fuente: 15M.

GRÁFICO III. ISSUES EN LOS MENSAJES DEL DISCURSO MEDIÁTICO DEL 15-M

\begin{tabular}{|l|c|c|}
\hline \multicolumn{1}{|c|}{ ISSUES } & TOTAL ISSUE & PORCENTAJE \\
\hline Movilización Ciudadana & 48 & 10,54 \\
\hline Crítica al Sistema Político & 58 & 12,74 \\
\hline $\begin{array}{l}\text { Crítica al Sistema } \\
\text { Financiero }\end{array}$ & 44 & 9,67 \\
\hline Corrupción Política & 40 & 8,79 \\
\hline
\end{tabular}




\begin{tabular}{|l|c|c|}
\hline $\begin{array}{l}\text { Indignados en el Resto del } \\
\text { Mundo }\end{array}$ & 17 & 3,73 \\
\hline Desempleo / Precariedad & 38 & 8,35 \\
\hline $\begin{array}{l}\text { Juventud Formada sin } \\
\text { Futuro / Generación } \\
\text { Perdida }\end{array}$ & 35 & 7,69 \\
\hline $\begin{array}{l}\text { Cambio de Sistema / } \\
\text { Propuestas }\end{array}$ & 49 & 10,76 \\
\hline $\begin{array}{l}\text { Necesidad de Toma de } \\
\text { Conciencia / Despertar }\end{array}$ & 17 & 3,73 \\
\hline $\begin{array}{l}\text { Derechos Sociales / } \\
\text { Inversión de Valores }\end{array}$ & 50 & 10,98 \\
\hline Redes Sociales & 28 & 6,15 \\
\hline $\begin{array}{l}\text { Censura a libertad } \\
\text { expresión por parte del } \\
\text { Sistema / Indiferencia }\end{array}$ & 31 & 6,81 \\
\hline TOTALES & 455 & 100 \\
\hline Fuente: Elaboración propia. & & \\
\hline
\end{tabular}

Es el momento de analizar qué es lo que se dice dentro de ese entramado de funciones del lenguaje y de la imagen publicada. El "qué" es la esencia, lo que se quiere transmitir, el "cómo" es la forma, el modo en que se dice. A continuación, gracias al estudio de los issues en la tabla sobre estas líneas, veremos ese "qué" se dice (ver Gráfico III).

La "crítica al sistema político" es el issue nombrado en mayor número de veces en los mensajes emitidos por los indignaos del $15-\mathrm{M}$ con un $12,74 \%$ del discurso; seguido del issue que alude a la pérdida de derechos sociales mediante la inversión de valores que está sufriendo la sociedad, con un 10,98\% del discurso. Ambos son los temas "estrella" mencionados por los activistas del 15-M. A lo que le siguen una serie de propuestas para cambiar el sistema, con un $10,76 \%$, lo cual no hace sino desvelar que, a pesar de incidir en la crítica al sistema y status quo, también y, a su vez, proponen nuevas alternativas de gestión para con el sistema actual.

Asimismo, invitan a la movilización ciudadana en sus textos con un 10,54\% del contenido apelativo a los ciudadanos. Y ya por debajo de éste, se sitúa la crítica al sistema financiero actual con un 9,67\%. A éste le siguen la "corrupción política" con un $8,79 \%$ y el "desempleo y la precariedad" con un $8,35 \%$. A tenor de esta última variable, le sigue la del desempleo juvenil y la generación perdida con un $7,69 \%$. 
A destacar, La censura de la libertad de expresión, como hecho impensable en un contexto democrático, se está dando desde el sistema para con los activistas. El $6,81 \%$ de los datos lo demuestran. Mientras que éstos intentan movilizarse y mover a la población a través de las redes sociales, issue al que se alude en un $6,15 \%$ del discurso.

Como valores menores en la escala de medición y contabilización de issues, están igualados con un 3,73 los valores de "Necesidad de toma de conciencia" y "otros indignaos por el mundo".

Como análisis de estos resultados se debe destacar el rechazo al actual sistema político por parte de los indignados; éstos insisten en que a causa de dicho sistema, junto con sus derivados intereses económicos, se ha generado una inversión de valores, deshumanizando al ser humano en pro de monetarizar al hombre como moneda de cambio. Así mismo, y casi a la par, dichos activistas proponen nuevas ideas y propuestas para una sociedad más justa e igualitaria, poniendo freno a la paulatina y creciente disparidad y desigualdad entre los individuos. Por lo tanto, existe un equilibrio real entre las críticas y las propuestas de cambio por parte de los Indignaos del 15-M.

\subsection{Nivel cualitativo}

La comunicación a analizar en el presente texto abarca tanto imágenes como textos convertidos en imagen, así como expresividad gestual de los sujetos fotografiados, todos ellos con un mismo origen e intencionalidad: la de comunicar socialmente. Se trabajará la imagen funcional dado que responde a una necesidad comunicativa y es producida precisamente con el objeto de satisfacerla (Gubern, 1987). Autores como Roland Barthes (1973 y 2003) con su 'Retórica de la Imagen' y sus parámetros de denotación y connotación; Umberto Eco a un nivel más profundo explicando el paso de la retórica a la ideología con la "Estructura Ausente" (Eco, 1973); y, finalmente Arnheim (1976) analizando las funciones de la imagen y los lenguajes de la connotación son autores que se dan cita en este análisis por sus aportaciones metodológicas en el estudio de la comunicación persuasiva que ocupa el presente análisis empírico.

Para hacer una mejor aclaración al lector, a través de la imagen funcional, se transmite, en cada soporte publicado, los valores que el emisor quiere transmitir al espectador. No estamos sino hablando de un gran signo que, como bien diría Eco (1976), pone en relación el plano de la expresión o significante, representado a través de la publicación, con todos sus símbolos, y el plano del contenido o significado, aquél que es más difícil definir por su intangibilidad, pero no menos fuerza, pues hablamos de una estructura de valores que construye el entorno $y$, por ende, la significación que quiere transmitirse mediante la "puesta en escena" de la creación fotográfica o de la iconización del texto en la imagen.

\subsubsection{RETÓRICA DE LA IMAGEN. DENOTACIÓN Y CONNOTACIÓN}

A continuación se expone un cuadro con las fotografías e imágenes analizadas: 
GRÁFICO IV. IMÁGENES DEL MOVIMIENTO DE INDIGNADOS

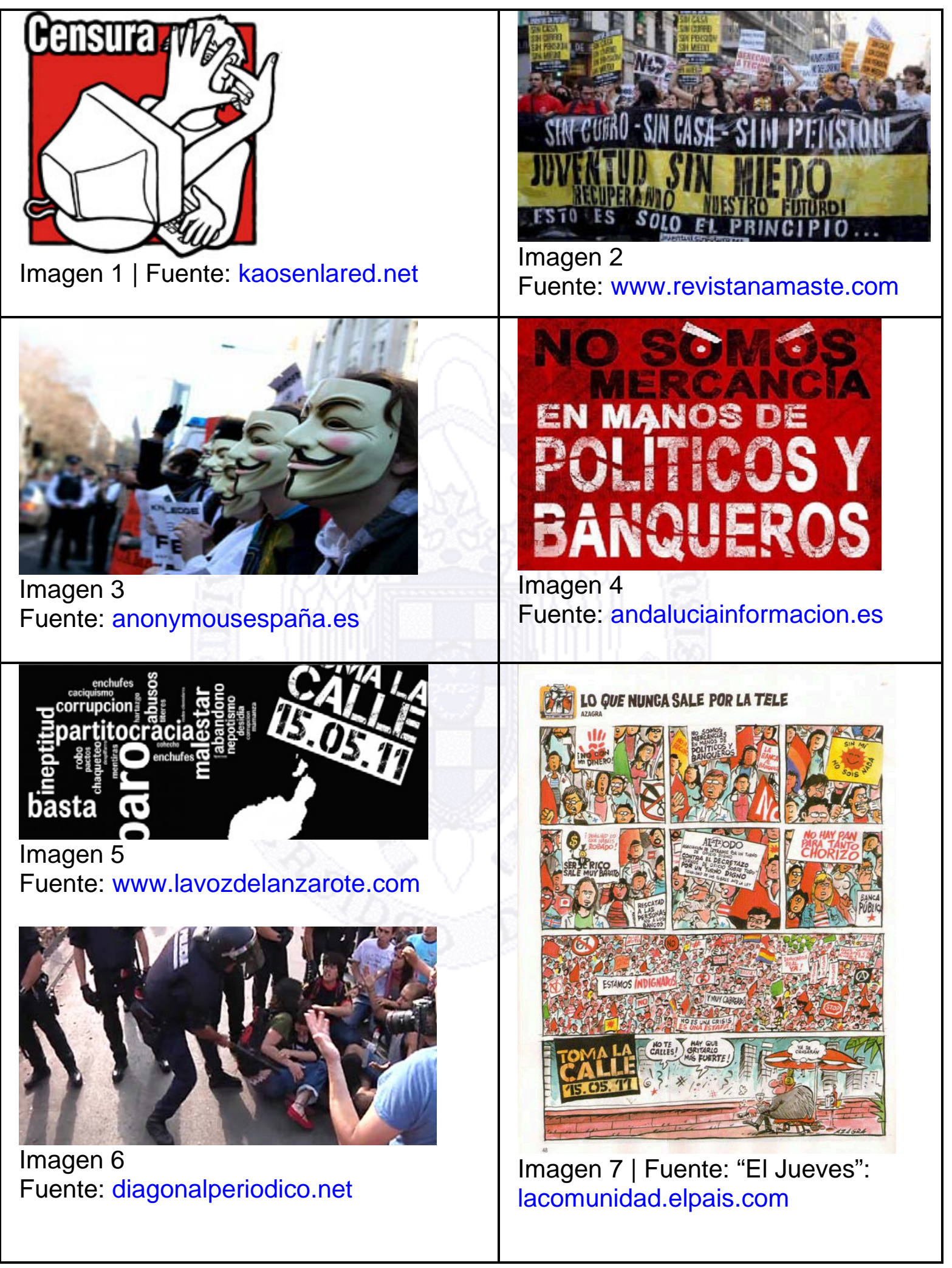


La imagen denotada ${ }^{3}$ está compuesta por lo que en ella se exhibe (Barthes, 2002), en el caso de la Imagen 1: Texto censura y metáfora gráfica, composición sobre fondo color rojo carmín; la connotación ${ }^{4}$ comienza a partir de esa composición denotada. Ante nosotros, en este caso concreto, se plasma una remetáfora en la significación sumatoria de texto e imagen. El texto escrito "Censura" se iconiza a través de la composición, a sí mismo, ejerce una función de relevo complementando en significado al texto, es decir, texto e imagen dicen lo mismo -frente al anclaje, donde el texto o la imagen ancla uno de los significados posibles al otro que posee un número $\mathrm{n}$ de significados en potencia; mediante el anclaje se actualizaría uno de esos $\mathrm{n}$ significados en potencia-. Paralelamente, la imagen icónica muestra esa censura textual gráficamente, de este modo "la metáfora hace que la significación denotativa se transforme en significación connotativa, en cuanto que el sentido transferido toma el lugar de la denotación" (Feliu, 1983, p. 121).

Por otro lado, el color de fondo utilizado es de la gama de los cálidos, asociándose a la luz solar y al fuego; es connotativo (Arnheim, 2001) porque no es un elemento descriptivo, sino con significado psicológico y cultural. De hecho el color rojo de la imagen significa vitalidad y pasión; es un color cálido, a la vez que agresivo, por lo que también se asocia con la violencia, el peligro, la guerra y la sangre. Por lo tanto, en esta imagen se quiere mover emocionalmente al receptor a través de esos signos y símbolos psicológicos, así como de la retórica utilizada, fomentando la toma de conciencia y el despertar social a lo que está aconteciendo.

En la Imagen 2, nos encontramos una fotografía, una imagen de carácter epistémico (Arnheim, 1976) que no hace sino hacer referencia a la realidad, es un fragmento de realidad de una manifestación. Jóvenes sin un futuro, una generación que se aventura perdida y que sale a la calle a gritar sus derechos y las injusticias del sistema. Se observado el uso de la dinámica del punto y el plano $^{5}$ en la imagen, ésta aparece como subdividida en dos horizontales. La fotografía posee un peso generado en la parte superior por los jóvenes, que es compensado por las grandes letras de la pancarta de la parte inferior. Existe un equilibrio en los pesos y cabe destacar la frase "sin curro, sin casa, sin pensión" como elemento divisorio de la horizontalidad. Al situarse éste junto a las grandes letras verticalizadas "Juventud sin miedo", hacen que esta frase y aquélla sean los grandes pesos visuales a los que tenderá a enfocarse en lector.

La intertextualidad (Rodríguez y Mora, 2002) entre el movimiento conocido como "Anonymous" (Imagen 3) y la película "V for vendetta" se hace patente a través de sus máscaras como símbolo que une a ambas, como elemento transmisor de valores de ésta sobre aquélla. Esos valores son la crítica al sistema totalitario en que se está convirtiendo la sociedad actual y el intento de liberación de los ciudadanos mediante la intelectualidad y el rescate a la conciencia con respecto de aquellos que intentan someternos a través del terror, del poder y de sus mentiras. Hablaríamos de una nueva intertextualidad o género intertextual "cine-

\footnotetext{
3 Aquella que transmite una información literal, análoga a la realidad enfocada.

${ }^{4}$ Elemento que apela a la ideología popular y contextual de los propios receptores.

${ }^{5}$ Técnica que se utiliza para aportar dinamicidad y tensión o simetría y equilibrio en la imagen.
} 
sociedad", donde una película inspira un movimiento social; que no al contrario, donde muchas obras cinematográficas se inspiran en la sociedad y sus movimientos. En este caso el proceso se invierte, la paradoja de la ficción sobre lo real, donde se da verosimilitud a lo que no lo es para designar aquello que es real. Así funciona el intertexto Anonymour- $V$ for Vendetta.

Tanto en la Imagen 4, como 5, se produce una iconización del texto. Éste es convertido en imagen con fines simbólicos y estéticos. En el primer caso, el fondo vuelve a mostrar un color rojo intento que, como ya hemos visto, es un color connotativo: vital, pasional, cálido y agresivo (Arnheim, 2001). Paralelamente, se produce una iconización en "SOMOS", donde las "oes" -recordando los "Caligramas del poeta francés Apollinaire"- ya no son grafemas, sino que se convierten en elementos no grafemáticos, pero sí gráficos. Añadiéndoles dos puntos y dos líneas blancas, denotan dos ojos; estudiando la configuración y composición de esos elementos connotan enfado, ojos iracundos. Paralelamente, en ambas imágenes, se utiliza un lenguaje claro, conciso, directo e imperativo. En el segundo caso (Imagen 5), se intenta mover al espectador manifestando "Toma la calle" y "Basta", ambos mensaje insertos estratégicamente en esa imagen. Pues, el ojo humano -en Occidente- ejerce un barrido sobre la imagen en forma de " $\mathrm{Z}$ " , la parte derecha es preponderante sobre la izquierda en el peso de lectura, el ojo tiende a ir hacia esta posición desde su complementaria; en el barrido, a pesar de existir un parámetro en vertical-horizontal, tiende a ejercer el recorrido izquierda-derecha, arriba-abajo. Por lo tanto, no es espontáneo el hecho de situar el mensaje "Toma la calle" en la posición derecha-superior, pues se convierte en el primer foco de atención para el ojo humano; el segundo foco de atención es "Basta" como pico inferior izquierdo del recorrido en " $Z$ ". Pululando alrededor de éstos, numerosos mensajes negativos -malestar, ineptitud, partitocracia, etcinundan el manifiesto publicitario. Por lo tanto, analíticamente se desvela un imperativo a la sociedad y una toma de conciencia donde se intenta poner límites a un sistema que ya no funciona en pro del ciudadano, sino todo lo contrario.

El contexto donde aparece inserta la Imagen 6 , se circunscribe a una noticia de prensa que habla de una sentada pacífica en la Plaza de Cataluña en Barcelona. A pesar de ser pacífica, los mossos de escuadra hirieron a numerosos acampados. Es una imagen que muestra la paradoja del sistema, transformando el bienestar en malestar social, desde los propios "cuidadores" sociales. Se trata de una imagen plenamente epistémica y referencial, fiel a la realidad, donde la imagen aporta informaciones visuales sobre el mundo, es decir, no arbitrarias, sino referentes a los hechos (Arnheim, 1976). Los hechos, en este caso -y en algunos más del 15-M- han mostrado revolución pacífica por parte de los indignados, a la par de ira y odio por parte de las fuerzas de seguridad. Unos hechos que dejan en evidencia a éstos y no hacen sino mostrar, paralelamente el tesón y la capacidad de lucha y de insurrección pacífica de aquéllos, tal y como un día fue evocada a través de figuras como Mandela, Martin Luther King o Gandhi.

Para concluir, la Imagen 7 es plenamente estética a modo de cómic, donde la

${ }^{6}$ Generada por los movimientos oculares sobre el papel y el orden de lectura -de izquierda a derecha y de arriba hacia abajo. 
retórica y el arte son los transmisores del movimiento social del 15-M. Los mensajes que se gritan en las calles españolas se reproducen en esta composición: "No con mi dinero", "No hay pan para tanto chorizo", "Rescatad a las personas, no a los bancos", "Estamos indignaos", "No te calles", "No es una crisis, es una estafa", etc. Paralelamente, cabe destacar que lo que sorprende, sobremanera, es la pasividad y soberbia con la que recibe todos los mensajes de denuncia uno de los "poderosos" del país -véase justo abajo del cómic- dónde afirma: "Ya se cansarán". Lo cual desvela, ya no su falta de conciencia y empatía para con los ciudadanos, el malestar y la precariedad social; sino que, además, con esas palabras transmite su seguridad, la seguridad de que se va a permanecer en esos parámetros perpetuando el status quo del sistema para con la sociedad española y tratando como a objetos, que no llegan ni a sujetos, infantiloides a la ciudadanía española.

\section{EL MANIFIESTO DE LOS INDIGNADOS Y LAS PROMESAS ELECTORALES DEL 20N}

\subsection{Del Mayo del 68 al 15-M}

Los movimientos sociales parecían haber perdido fuerza tras los discursos de Sartre y el Mayo del 68. Así, señala Sthepane Hessel al referirse a la crisis económica del siglo presente y el silencio de la sociedad ante dicha situación (Hessel, 2011). En este contexto, ha surgido la reciente indignación de amplios sectores y grupos de la sociedad civil que se han organizado en movimientos en contra del sistema político y económico que ha provocado la depresión financiera. Podemos citar entre ellos, la revolución silenciada de Islandia ${ }^{7}$ y el movimiento del $15 \mathrm{M}$ en España.

Los manifiestos de estos movimientos sociales, en concreto $15 \mathrm{M}$ y Democracia Real Ya, han ofrecido una serie de propuestas de cambio. Aquí es donde surge la pregunta sobre la independencia o dependencia de los colectivos civiles hacia la estructura política. Al respecto, algunos teóricos sostienen que la ciudadanía corriente carece de voz propia y son los partidos quienes controlan la expresión de la opinión pública (Manin, 1998). En sintonía, la teoría liberal de la información afirma que los ciudadanos no tienen madurez política y es una élite política la responsable de la gestión (Lippman, 2003). Independientemente de una postura u otra, el punto de partida común que asumen es que la supuesta autonomía de la sociedad civil en la práctica política es más un postulado normativo que un análisis fruto de la evidencia empírica.

Por tanto, vuelve a surgir la duda sobre si el 15M es un movimiento autónomo con respecto a las características propias de las poliarquías (Dahl, 1999), o si bien, por el contrario, existe cierta cercanía hacia determinadas opciones políticas. ¿Hasta qué punto algunos partidos han capitalizado este movimiento tanto en su proceso (politics) como en la elaboración de propuestas políticas (policy) para su

$7 \quad$ Para más información sobre el caso islandés se puede consultar: http://www.elimparcial.es/contenido/80620.html 
implementación de cara a las elecciones generales del 20N?

\subsection{Las propuestas de los indignados y su capitalización por parte de los partidos}

En ese sentido, planteamos la pregunta de cuál de los partidos políticos ha estado más próximo a las demandas del $15 \mathrm{M}$ en sus programas políticos durante la campaña. En sí, nuestro interés no reside en demostrar si existe una relación de causalidad o de correlación entre el surgimiento de estos partidos y la introducción de sus líderes y élites dentro de los grupos políticos. Al contrario, pretendemos observar si existe lejanía o cercanía con respecto a alguna opción política, teniendo en cuenta la postura de crítica a la clase política y el recorte de sus "privilegios" mantenida por los indignados. La hipotética inclusión de determinados sujetos provenientes del $15 \mathrm{M}$ en algunos partidos es una labor que bien corresponde a otro trabajo de investigación.

Para ello, analizamos las propuestas de tres partidos políticos, a saber: PSOE, UPyD e IU, a través de la comparación de sus programas con el manifiesto de los indignados, el análisis de noticias en prensa y las declaraciones de los responsables de las campañas. ¿Por qué seleccionamos estos partidos? Básicamente, porque el Partido Popular se sitúa en una posición bien distinta con respecto a las demandas de los indignados y porque gran parte de sus propuestas ideológicas pueden ser encuadradas en posturas cercanas a la izquierda política.

De esta forma, para tomar perspectiva con otros movimientos es preciso señalar que el objetivo del movimiento es transformador, pero no rupturista y que surge en un escenario de descontento con la situación económica (Santamaría, 2011), a diferencia del Mayo del 68. La metodología comparativa empleada entre las agendas de los citados partidos la hemos estructurado a partir de tres "issues" en el manifiesto del 15M: sistema electoral y corrupción política, empleo y jubilación y mercado financiero.

Así, apostamos por una comparación de los "issues" por considerarlos uno de los elementos más válidos para explicar el comportamiento político de los sujetos en los últimos años. De hecho, las últimas investigaciones sobre los factores que influyen en la decisión de voto no son tanto los cleveages definidos por Lipset y Rokkan (Thomassen, 2005), como otros elementos correspondientes al cambio experimentado por las sociedades postindustriales desde la primera década del siglo XX hasta los sesenta.

\subsection{Análisis de la agenda del 15M y los programas electorales de la izquierda política}

En primer lugar, la demanda de los indignados en torno al sistema político se centra en la reforma del sistema electoral para mayor proporcionalidad y la lucha contra la corrupción, siendo uno de los principales "issues" sobre los que los distintos partidos analizados propusieron una serie de medidas al respecto. Aquí valoramos el "issue" referente al sistema electoral y corrupción política. Veamos a 
continuación:

a) EI PSOE ofrece un consenso de sistema electoral en torno al modelo alemán con listas desbloqueadas y un aumento de la paridad y la creación de una agencia dirigida a la corrupción en materia urbanística y la creación de códigos de conducta.

b) IU incide en la reforma de los elementos del sistema que crean desproporcionalidad. Asimismo, como una ley anti-corrupción, la disminución salarial de los políticos, pérdida de las inmunidades y eliminación de cargos de libre designación.

c) UPyD, plantea una serie de cambios del sistema electoral en sintonía con la propuesta con IU. A la par, señalan una propuesta de ley en contra de la corrupción, mejoras en el derecho a la información y modificaciones penales, cambios en los requisitos del cargo público y supresión de las pensiones de parlamentarios.

En segundo lugar, el 15-M profundizó en el paro juvenil, la reforma laboral que disminuye la indemnización por despido y el aumento de la jubilación y la base reguladora de la pensión. Así, se encuentran los grandes temas del ambito de políticas sociales y laborales que tanta fuerza ha tenido dentro de los debates de los indignados. En relación a ello, los partidos plantean:

a) EI PSOE destaca un Plan de Empleo para Jóvenes dirigidos a aquellos más perjudicados y con menos formación entre dicho colectivo y en general. Por otro lado, no constan grandes referencias al sistema de pensiones. Esta ausencia de pronunciación al respecto está vinculada a un debate todavia inconcluso entre los principales partidos europeos y las instituciones comunitarias sobre la rentabilidad de dichas modificaciones para el mantenimiento de los sistemas de bienestar.

b) IU propone la primacía de la búsqueda de empleo, unido a estímulos en PYMES y autónomos. En cuanto a las pensiones, se opone al aumento de la edad de jubilación y la base reguladora junto a una norma que actualice su financiación después del Pacto de Toledo. Lo que la lleva a continuar con la secuencia de antiguos pactos en materia socio-económica que se había venido desarrollando en España desde el Gobierno de Suárez con los Pactos de la Moncloa y que continuaron en adelante con otros acuerdos simiilares durante los ochenta y los noventa.

c) UPyD plantea la reforma del mercado laboral (excepto los empleos temporales justificados, de la negociación colectiva y una apuesta por la contratación a tiempo parcial). Para la jubilación ofrecen regular la flexibilización de la edad de jubilación y correcciones en su financiación. Por lo que, proponen medidas de corte liberal, pero que permitan mantener el sistema de bienestar tal y como se venido disfrutando hasta ahora.

En tercer lugar, la culpabilidad del sistema financiero en la crisis en contraste con las políticas de inyección de liquidez y la reforma de las cajas de ahorros representan las propuestas de los indignados en materia bancaria. Por su parte, las fuerzas políticas disponían: 
a) PSOE ofrece una mayor colaboración entre Estado y sistema bancario en la supervisión financiera y en los inversores. Así, como un aumento de los impuestos progresivos y la modificación de otros para aumentar la igualdad. Por lo que, adoptar una perspectiva que lo separa de ciertas posturas más radicales de los indignidos dirigidas a condenar a las élites financieras por su responsabilidad en la crisis económica, queda fuera de su estrategia, ya que le haría perder el número de votos de los indecisos.

b) IU destaca la creación de una banca cívica y la reforma intensa del sistema de cajas de ahorro, especialmente en la designación y jubilación de los miembros de los consejos de administración. No obstante, no se observan otras prospuestas que no vayan más allá de la preocupación por la composición de los órganos y la prolongación de nuevas atribuciones al sistema de cajas de ahorros.

c) UPyD propone correcciones en las formas de designación de los miembros de los consejos, la condicionalidad en las ayudas estatales y la no intromisión de los gobiernos autonómicos en las fusiones entre cajas. Además de reformas en la independencia del Banco de España y el funcionamiento de las agencias de rating.

Tras la presente comparación, observamos una serie de patrones en las agendas planteadas por los distintos partidos políticos (Gráfico V). Por su parte, el PSOE intenta adoptar algunas posturas cercanas a los indignados como ligeras reformas en el sistema electoral, un plan de empleo para jóvenes y la búsqueda de mayor igualdad en los impuestos. No obstante, su falta de pronunciación sobre cuestiones como la edad de jubilación o una reforma en profundidad del sistema electoral, le produce cierta lejanía si lo comparamos con IU y UPyD.

\section{GRÁFICO V. ISSUES DE LOS PARTIDOS PARA EL 20N EN RELACIÓN CON EL MANIFIESTO 15M}

\begin{tabular}{|c|c|c|c|}
\hline $\begin{array}{ll}\text { Issue } & \text { I } \\
\text { Partido } & \end{array}$ & PSOE & IU & UPyD \\
\hline $\begin{array}{l}\text { Sistema } \\
\text { electoral y } \\
\text { corrupción } \\
\text { política }\end{array}$ & $\begin{array}{l}\text { Cambios en los } \\
\text { elementos del } \\
\text { sistema. } \\
\quad \text { Paridad. }\end{array}$ & $\begin{array}{l}\text { Eliminación de } \\
\text { elementos } \\
\text { desproporcionales } \\
\quad \square \text { Disciplina } \\
\text { política. } \\
* \quad \text { Eliminación de } \\
\text { prerrogativas } \\
\text { parlamentarias. }\end{array}$ & $\begin{array}{l}\text { Discip } \\
\text { lina política. } \\
\text { ndización } \\
\text { derecho de } \\
\text { información. }\end{array}$ \\
\hline
\end{tabular}




\begin{tabular}{|c|c|c|c|}
\hline $\begin{array}{l}\text { Empleo y } \\
\text { jubilación }\end{array}$ & $\begin{array}{l}\text { Plan de empleo } \\
\text { juvenil. } \\
\text { pronunciación sobre } \\
\text { pensiones. }\end{array}$ & $\begin{array}{l}\text { Búsqueda de } \\
\text { empleo. } \\
\quad \text { Pymes. } \\
\quad \text { No aumento } \\
\text { edad de jubilación. }\end{array}$ & $\begin{array}{l}\text { Refor } \\
\text { ma mercado } \\
\text { laboral. } \\
\text { ilidad de } \\
\text { edad de } \\
\text { jubilación. }\end{array}$ \\
\hline $\begin{array}{l}\text { Mercado } \\
\text { financiero }\end{array}$ & $\begin{array}{l}\text { Colaboración } \\
\text { Estado-sistema } \\
\text { financiero. } \\
\text { Reforma de } \\
\text { impuestos. }\end{array}$ & $\begin{array}{l}\text { Banca civica. } \\
\text { composición de } \\
\text { consejos de cajas de } \\
\text { ahorros. }\end{array}$ & $\begin{array}{l}\text { Refor } \\
\text { ma en } \\
\text { composición } \\
\text { de consejos } \\
\text { de cajas de } \\
\text { ahorros. } \\
\text { enencia del } \\
\text { banco de } \\
\text { España. } \\
\text { ar agencias } \\
\text { de rating. }\end{array}$ \\
\hline
\end{tabular}

Fuente: Elaboración propia a partir de los programas electorales de PSOE, IU y UpyD para las elecciones generales de 2011

Al analizar estas dos opciones políticas, observamos como se produce un trasvase más intenso desde el Manifiesto del 15M, hacia los programas electorales de ambos partidos. Lo que diferencia a grandes rasgos a uno y otro, es que IU adopta de forma más explícita y directa cuestiones como la imposición de disciplina política a los parlamentarios, la supresión de las prerrogativas de los miembros de los órganos legislativos y la creación de una banca cívica entre otros. Por su parte, UPyD se mantiene en una postura que podríamos afirmar como más "políticamente correcto". De hecho, intenta mantener cierta lejanía no en las propuestas, sino en la capitalización directa no ya sólo de ideas, sino incluso de líderes y miembros destacados de los indignados.

Así, de la anterior comparativa se expresa una mayor lejanía del PSOE hacia los indignados, especialmente en la colaboración público-privada en el sistema financiero y el camino hacia un modelo electoral "a la alemana". Por su parte, IU y UPyD manifiestan una menor distancia hacia las propuestas del 15M debido a que plantean grandes similitudes en la reforma del sistema electoral, la reforma de las cajas de ahorros y las alternativas al aumento de la edad de jubilación. 


\section{CONCLUSIONES}

Por un lado, aventuramos la estrategia lingüística y simbólica del 15-M a través de un estudio de doble vertiente: cuantitativo, a través de un análisis de contenido o "issues", así como de las funciones del lenguaje y la imagen; parejo a un análisis cualitativo, donde se desvela qué se connota tras a denotación gráfica mediante la retórica de la imagen publicada.

En el primer caso, el cuantitativo, descubrimos una preponderancia de la función emotiva del lenguaje y simbólica de la imagen, es decir, se intenta conmover y emocionar al lector mientras predominan unas imágenes transmisoras de valores ligados, en mayor grado, a la libertad y la toma de conciencia ciudadana. Con respecto a ese issue o tema principal en el discurso mediático se desvela la "crítica al sistema político" como más reiterativo en las publicaciones, seguido de la protesta de la "pérdida de derechos sociales".

En el segundo caso, el cualitativo, se dan cita fenómenos como la intertextualidad de géneros, en este caso "cine-sociedad" -véanse, por ejemplo, las máscaras del grupo Anonymous-; la crítica al sistema a través de metáforas visuales; la utilización de la psicología de la composición y el color con fines persuasores; así como la emisión de imperativos lingüísticos, iconizados gráficamente, como transmisores de contenido simbólico a la ciudadanía.

Por otro lado, el análisis de programa manifiesta una mayor cercanía de UPyD e IU al movimiento $15 \mathrm{M}$ y la menor del PSOE. En dicho trabajo comparativo, es imposible diferenciar o graduar de alguna forma la distancia de UPyD e IU, ya que ambos recogen propuestas inspiradas en los discursos de los indignados. Por lo que, es preciso recurrir a las inferencias extraídas del análisis hemerógrafico sobre las entrevistas a los responsables de las campañas electorales.

Si bien es una tarea ardua aclarar cuál de los dos se ha acercado más a los indignados, el análisis de prensa desvela el intento de UPyD por mostrar a IU como más próxima a los indignados y a ésta por definirse como independiente de la intención de voto de los mismos. Por tanto, podemos afirmar que el partido político que ha expresado una mayor cercanía con respecto a los indignados en las citadas elecciones es IU, siendo la opción política que más nítidamente ha capitalizado el movimiento de los indignados que en un primer momento se presuponía independiente de la partitocracia española y lo ha convertido en un recurso más a disposición de su estructura política. Así, no se cumple el tradicional principio de autonomía que los pluralistas citan en sus postulados sobre la independencia de los colectivos de la sociedad civi (Dahl, 1999).

Como broche a esta investigación, se hace patente, a través de los mensajes de los "Indignaos", que la supremacía del sistema económico ha llegado a envolver el perímetro del poder político; según ellos, éste, lejos de mantener sus valores e ideales iniciales, se ha sometido a las reglas de aquél. Se habla de una crisis de valores pareja a una económica, donde los medios de comunicación han jugado un rol protagonista: "La trampa se encuentra en esa hélice simbólica que nos atrapa...hacia un sistemático comportamiento consumista que se ha forjado en el entramado cultural de nuestros días" (Juan-Amat, 2009, p. 167). 


\section{BIBLIOGRAFÍA}

(1987) ALVAR, Manuel, El lenguaje político, Fundación Friedrich Ebert, Madrid.

(1976) ARNHEIM, Rudolf, El Pensamiento Visual, Eudeba, Buenos Aires.

(2001) Arte y percepción visual, Alianza, Madrid.

(1972). BARTHES, Roland, "Retórica de la Imagen". En AA.VV., Análisis de la Imágenes, Tiempo Contemporáneo, Buenos Aires.

(2002). Lo obvio y lo obtuso, Paidos, Barcelona.

(1952) BERELSON, Bernard, "Content analysis in communication research". En AA.VV., The free press, Glencoe (Illinois).

(2011) COLLADO, Francisco; JUAN-AMAT, Ana María y JIMÉNEZ, José Francisco, "Redefiniendo un líder en el proceso de comunicación política: el caso de Mariano Rajoy en el contexto de 2008", Actas del X Congreso de la Asociación Española de Ciencia Política y de la Administración. Universidad de Murcia, Murcia.

(2011) CRESPO, Ismael et al., Manual de comunicación política y estrategias de campaña, Biblos, Buenos Aires.

(2011). DE ROSA, Sofía, "Movimiento 15-M: ¡Cuidado que viene el ciudadano!", Más poder local, No. 6, ISSN 2172-0223, pp. 6-19.

(1969) EASTON, David, Enfoques sobre teoría política, Amorrortu, Buenos Aires.

(1973) ECO, Umberto, La estructura ausente, Lumen, D.L., Barcelona.

(1976). Signo, Labor, D.L, Barcelona.

(1983) FELIU, Emilio, "Publicidad y connotación: el mensaje de inferencia". En AA.VV., Estudios de lingüística. ELUA, Alicante.

(1987) GUBERN, Román, La mirada opulenta: Exploración de la iconosfera contemporánea, Gustavo Gili, Barcelona.

(2011) HESSEL, Sthepane, ¡Indignaos!, Destino, Barcelona.

(1974). JACOBSON, Roman, "Closing Statements. Linguistics and Poetics". En T.A. Sebeok (ed.), Style in Language (La lingüística y la poética).

(2009) JUAN AMAT, Ana María. "Publicidad y Sociedad. De la denotación imaginaria a la connotación real", Barataria, Revista Castellano-Manchega de Ciencias Sociales, No. 10, ISSN 1575-0825, pp. 165-173.

(2011) JUAN AMAT, Ana María y JUAN-AMAT, Isabel, "La fuerza de un slogan: el mensaje del pueblo. 15-M, Spanish Revolution". Revista Politeia, No. 57, pp. 3139.

(1985) KRIPPENDORF, Klaus, Content analysis: an introduction to its methodology, Sage, Beverly Hills.

(1993) LINDBLOM, Charles y WOODHOUSE, Edward, The policy-making process, Prentice-Hall, New Jersey. 
(2003) LIPPMAN, Walter, La opinión pública, Langre, San Lorenzo del Escorial.

(1998) MANIN, Bernard, Los principios del gobierno representativo, Alianza, Madrid.

(1976). PÉNINOU, George, Semiótica de la publicidad, Gustavo Gili, Barcelona.

(2011): PINILLA, Alfonso, "La percepción del movimiento "15-M" en las ediciones digitales de El Mundo y El País", Tejuelo, No. 12, ISSN 1988-8430, pp. 196-217.

(2002) RODRÍGUEZ, Raúl y MORA, Kiko, Frankenstein y el cirujano plástico: una guía multimedia de semiótica de la publicidad, Publicaciones de la Universidad de Alicante, Alicante.

(2011) SANTAMARÍA, Antonio, "La rebelión de los indignados: reflexiones a pie de acampada". El Viejo Topo, No. 282-283, 21-25.

(2005) THOMASSEN, Jacques, The European voter, Oxford University Press, Oxford.

\section{DOCUMENTALES}

- Indignaos, el documental del 15-M. Fuente: La Noria, Canal de TV Telecinco.

- El 15-M según France. Fuente: Segunda Cadena de TV pública francesa, subtitulado al castellano a través de la plataforma youtube.com.

\section{PROGRAMAS Y DOCUMENTOS POLÍTICOS}

- Movimiento 15M (2011). Manifiesto del 15M.

- Izquierda Unida (2011). Propuestas electorales Izquierda Unida, elecciones 2011.

- Partido Socialista Obrero Español (2011). Programa electoral: elecciones generales 2011.

- Unión, Progreso y Democracia (2011). Elecciones Generales 2011: Programa electoral. 